\title{
Réplique au compte rendu de Jocelyn Létourneau sur Cité libre. Une anthologie (Montréal, Stanké, 1991), paru dans le volume 46 numéro 2 (automne 1992) : 371-372.
}

\section{Yvan Lamonde}

Volume 46, numéro 3, hiver 1993

URI : https://id.erudit.org/iderudit/305142ar

DOI : https://doi.org/10.7202/305142ar

Aller au sommaire du numéro

Éditeur(s)

Institut d'histoire de l'Amérique française

ISSN

0035-2357 (imprimé)

1492-1383 (numérique)

Découvrir la revue

Citer ce document

Lamonde, Y. (1993). Réplique au compte rendu de Jocelyn Létourneau sur Cité libre. Une anthologie (Montréal, Stanké, 1991), paru dans le volume 46 numéro 2 (automne 1992) : 371-372. Revue d'histoire de l'Amérique française, 46(3), 556-557. https://doi.org/10.7202/305142ar d'utilisation que vous pouvez consulter en ligne. 
Réplique de Yvan Lamonde au compte rendu de Jocelyn Létourneau sur Cité libre. Une anthologie (Montréal, Stanké, 1991), paru dans le volume 46 numéro 2 (automne 1992): 371-372.

Dans la recension de notre ouvrage, Cité libre. Une anthologie, Jocelyn Létourneau a bien vu son caractère instrumental mais avoue être resté sur sa faim quant aux motivations de l'entreprise et aux critères de sélection des 
textes. Outre que l'avant-propos indique la nécessité de rendre disponibles des textes représentatifs d'une revue si souvent citée, une familiarité réelle avec les textes, une connaissance des travaux sur Cité libre cités en bibliographie et une lecture attentive de l'introduction, qui selon monsieur Létourneau n'ajoute rien aux Mémoires de Gérard Pelletier, lui auraient fait saisir à la fois le sens de l'entreprise et la logique de mon choix de textes.

L'interview avec Gérard Pelletier n'a rien de l'improvisation; les questions posées à $\mathrm{G}$. Pelletier en introduction sont autant de signes pour comprendre les sections de l'ouvrage et la cohérence d'un choix: la JEC (p. 7-8) est reliée aux textes sur l'atmosphère religieuse et fait voir l'origine et le sens de l'anticléricalisme de la revue; la question (8) sur le rapport entre démocratie et nationalisme qui ébablit «la centralité» de ce thème renvoie aux chapitres III et IV de l'anthologie; la question sur Mounier, auquel on réfère si souvent dans les études, précise l'origine et les limites de cette influence et prépare le lecteur au chapitre I. Quant aux questions sur la conscience historique de Cité libre à propos de l'histoire du libéralisme au Québec, sur l'absence relative de textes concernant la question sociale et sur la place de la revue en regard des périodiques en amont et en aval, elles font écho à des critiques ou à des questions soulevées dans les travaux sur Cité libre et je ne leur ai pas trouvé une réponse dans les Mémoires de monsieur Pelletier.

Jocelyn Létourneau ne prétend pas que «ma sélection soit mauvaise»; il eut été intéressant de lire ce qu'un connaisseur aurait exclus de ma sélection et ce qu'il aurait plutôt inclus. Une telle responsabilité eut obligé à dire ses propres choix et à serrer de plus près l'objet.

Le critique jongle ensuite avec le fait de la parution (fortuite) de l'anthologie et la relance de Cité libre, évoquant les «comme si» et les «textes fétiches». Un véritable connaisseur de Cité libre aurait vu ce qui constitue, pour moi, l'apport premier de cette anthologie: la mise en évidence de la dissidence à l'intérieur même de la revue, d'où le choix de «Matines», de «Pour clore un incident», de «Dissidence», du chapitre «Autres orientations» qui donne voix à la différence d'un Dumont, d'un Rioux ou d'un Vadeboncoeur; d'où, aussi, le choix du chapitre «Le débat Cité libre-Parti pris». S'agit-il, toujours, de perpétuer une «incantation»?

Quant à la bibliographie «très sommaire, pour ne pas dire décevante», le spécialiste aura oublié de nous souligner les études manquantes sur Cité libre et ne se sera pas souvenu de nos bibliographies sur l'histoire des idées au Québec publiées par la Bibliothèque nationale du Québec et dans Littératures (1989). 